\title{
Spontaneous alternation and emotionality in rats with differential early experience*
}

\author{
RICHARD H. O'CONNELL \\ California State University, Northridge, California 91324
}

\begin{abstract}
The relationship between emotionality measures and spontaneous alternation was tested using male rats which had been differentially handled as pups. Handled rats had less emotional open-field activity patterns over a 90-day period and alternated more than nonhandled rats.
\end{abstract}

The effect of fearfulness on the tendency of the rat to alternate spontaneously has been studied by manipulating characteristics of the testing environment (Lester, 1967a), selecting rats displaying individual differences considered indicative of emotionality (Heathers, 1940; Lester, 1967b), and manipulating the rat's early environment. Kirkby and Kirkby (1968) interpreted the greater alternation of an "enriched" early environment group as due to differences in learning ability rather than fearfulness because the groups did not differ in failure to leave the startbox within a 3-min limit. The present study used adult rats which had been differentially handled as pups by another E. Though the data reported reflect some improvement over the original in control of sex, litter control is not critical here, for the focus is on the relationship between emotionality, assessed behaviorally, and alternation, rather than on determining the role of specific early experience factors in producing emotionality differences.

\section{METHOD}

\section{Subjects}

The Ss were 14 male Wistar albino rats $180-190$ days of age which had been treated on 21 occasions during their first 3 weeks of life by Goldman (1965). The 7 rats, from two litters, in Group $\mathrm{H}$ had been handled by being removed from their living cages and placed in a black startbox for $3 \mathrm{~min}$. The mother was removed from the cage while the pups were successively treated. The 7 rats, from two litters, in Group NH had not been handled but the mother was removed daily for a comparable period (about $25 \mathrm{~min}$ ), and during this interval the startbox was placed in the living cage for $3 \mathrm{~min}$. The two groups used in this study were selected from Goldman's larger $\mathrm{H}$ and $\mathrm{NH}$ groups so as to be perfectly matched on tests given when the rats were 7 weeks old: 4 rats had received avoidance training in a black alley, 2 had received reward training in a black alley, and 1 received reward training in a white alley. Goldman tested all rats for 3 min in an open field at 84 and 85 days of age; her complete Group $\mathrm{H}$ was

* This investigation was supported in part by National Science Foundation funds through the Committee on Research, UCLA. The author wishes to thank Dr. Goldman for her cooperation. This paper was sponsored by Sally E. Sperling, who takes full editorial responsibility for its contents. significantly more active than Group NH. Goldman did not find that type of adult treatment significantly affected open-field measures. The Ss were maintained ad lib.

\section{Apparatus and Procedure}

The T-maze choice arms were $12.7 \times 56 \mathrm{~cm}$, and each terminated in a $19 \times 38 \mathrm{~cm}$ goalbox. The guillotine door in each arm was $24 \mathrm{~cm}$ from the goalbox. The gray startbox was $12.7 \mathrm{x}$ $21.6 \mathrm{~cm}$, separated by a glass door from a choice area $41.3 \mathrm{~cm}$ wide at its junction with the choice arms and tapering to a width of $12.7 \mathrm{~cm}$ at the glass door, which was $19 \mathrm{~cm}$ from the junction.

Because brightness preference might be accentuated by group differences and thus further separate the groups on alternation, liners of black or white posterboard covered the arm walls and floors and extended to the midline of the choice area. Plastic floor covers were wiped clean between rats.

Ss were handled briefly 1 day and tested in an open field on the next 2 successive days. Apparatus and test conditions on the first day were the same as those described by Goldman. The second test in the open field was a measure of latency of emergence from the individual living cage which was placed in the field against the wall. Then, on 2 successive days prior to the start of alternation tests, each rat was placed in the $\mathrm{T}$ startbox and allowed to spend $2 \mathrm{~min}$ in the choice area, though plastic plates prevented arm entry. In each group, three rats always had black on the left and four had black on the right.

Each rat was tested for alternation on 6 successive days with intertrial intervals (ITI) of 1,30 , or $60 \mathrm{~min}$. The rat was left in the goalbox area for $1 \mathrm{~min}$, then, during the two longer delays, returned to its home cage. Each interval was used twice with each rat in an order which was balanced for each rat and differed greatly within each group.

\section{RESULTS}

A repeated-measures analysis of variance was applied to the results of the initial pair of open-field tests administered to these rats by Goldman. The number of squares entered was greater for $\mathrm{H}$ than for $\mathrm{NH}$ rats $(\mathrm{F}=$ 5.23 , df $=1 / 12, p<.05)$, and activity on Day 2 was greater than that on Day $1(F=19.16, d f=1 / 12$, $\mathrm{p}<.01)$. The interaction of day and treatment was significant $(F=18.73$, df $=1 / 12, p<.01)$, due to an absence of significant difference between groups on Day 1 combined with the failure of $\mathrm{NH}$ rats to show an increase in activity from Day 1 to Day 2. 
The first new open-field test found $\mathrm{H}$ rats slightly more active and NH rats slightly less active than they had been on Day 2 of the first pair of tests; the difference between groups was again significant $(F=$ $29.26, \mathrm{df}=1 / 12, \mathrm{p}<.01$ ). The interaction of treatment and time was also significant $(F=3.69$, df $=2 / 24$, $\mathrm{p}<.05$ ), as $\mathrm{H}$ rats monotonically increased in activity while $\mathrm{NH}$ rats were most active in the second minute and least active during the third. On the second day of open-field testing, no $\mathrm{NH}$ rat emerged from his cage while three $\mathrm{H}$ rats emerged.

Duing alternation trials, 12 of the 14 rats showed a preference for the black side on first trials (binomial test; $p<.01$ ). The percentage of first trials to the black side was $73.8 \%$ for $\mathrm{NH}$ rats and $90.5 \%$ for $\mathrm{H}$ rats. Rats given shock avoidance training were responsible for the majority of white selections among NH Ss; they did not differ in alternation from other $\mathrm{NH}$ rats.

With 1-min ITI, $\mathrm{H}$ rats alternated on $64.3 \%$ of the tests and $\mathrm{NH}$ on $28.6 \%$. Treating the two tests as independent measures, the difference between the percentages $(p<.05)$ indicates these two groups did differ in spontaneous alternation (see Douglas, 1966, for a justification of the independence of these repeated measures). With 30-min ITI, the $\mathrm{H}$ rats alternated on $57.1 \%$ of the tests and the NH on $21.4 \%(p<.05)$. With 60 -min ITI, $21.4 \%$ alternation occurred in each group. A set of rats from the shocked group of Goldman's study was also tested, though it was not possible to match perfectly these rats with the other groups on adult experience. On open-field, brightness preference, and alternation measures, these male rats were very similar to the $\mathrm{H}$ group.

\section{DISCUSSION}

Goldman summed each rat's activity scores over two open-field tests and found handled rats more active. The third test, given 3 months later, again found handled Ss more active. This reliability with repeated measures is comparable to that found over the same age range with independent groups (Denenberg \& Smith, 1963). Goldman probably failed to find the interaction of day and treatment in her data because she combined the sexes in her analysis. Other studies support the conclusion that differential early handling may not be reflected in activity differences on the first open-field test, but only when the field has become more familiar (e.g., Livesey \& Egger, 1970). An analogous change over time was found within the third test: handled rats monotonically increased in activity and nonhandled nonmonotonically decreased. With relatively short ITIs, handled rats displa yed more alternation.

Wong (1969) failed to find an effect of handling on alternation tested with a new procedure which has not been fully described. Therefore, procedural differences may exist other than the introduction of reward. Both his $\mathrm{H}$ and $\mathrm{NH}$ groups apparently alternated at a chance level, and from the reported data it can be determined that $\mathrm{NH}$ rats alternated most when a right turn on Trial 2 was scored as alternation and, strangely, that $\mathrm{H}$ rats alternated most (runs test; $\mathrm{U}=2, \mathrm{p}<.29$ ) when a left turn was so scored. When his $\mathrm{H}$ and $\mathrm{NH}$ groups were satiated, the condition most interpretable, both groups displayed a comparably high percentage of alternation. This could have been a consequence of the procedure used; two initial trials, one forced, were given to one side prior to the alternation test, and the unentered side was altered, introducing response to stimulus change along with the possibility of alternation of brightness (cf. O’Connell, 1971).

If spontaneous alternation is viewed as dependent upon learning (O'Connell, 1965), one might interpret the greater alternation of handled rats as a function of the better learning and retention which may be shown by these rats (Nováková, 1966; Young, 1964). However, the open-field data suggest that the test procedures may produce less stress for handled rats and hence less stereotypy (DeValois, 1954).

\section{REFERENCES}

Denenberg, V. H., \& Smith, S. A. Effects of infantile stimulation and age upon behavior. Journal of Comparative \& Physiological Psychology, 1963, 56, 307-312.

DeValois, R. L. The relation of different levels and kinds of motivation to variability of behavior. Journal of Experimental Psychology, 1954, 47, 392-398.

Douglas, R. J. Cues for spontaneous alternation. Journal of Comparative \& Physiological Psychology, 1966, 62, 171-183.

Goldman, P. S. Conditioned emotionality in the rat as a function of stress in infancy. A nimal Behaviour, 1965, 13, 434-442.

Heathers, G. L. The avoidance of repetition of a maze reaction as a function of the time between trials. Journal of Psychology, $1940,10,359-380$.

Kirkby, R. J., \& Kirkby, J. E. Note: Early environmental experience and spontaneous alternation. Psychological Reports, 1968, 23, 1278.

Lester, D. Effects of fear upon exploratory behavior. Psy chonomic Science, 1967a, 9, 117-118.

Lester, D. Exploratory behavior of dominant and submissive rats. Psychonomic Science, 1967b, 9, 285-286.

Livesey, P. J., \& Egger, G. J. Age as a factor in open field responsiveness in the white rat. Journal of Comparative \& Physiological Psychology, 1970, 73, 93-99.

Nováková, V. Weaning of young rats: Effect of time on behavior. Science, 1966, 151, 475-476.

O'Connell, R. H. Trials with tedium and titillation. Psychological Bulletin, 1965, 63, 170-1 79 .

O'Connell, R. H. Spontaneous alternation of brightness? Psychonomic Science, 1971, 22, 273-274.

Wong, $R$. Alternation rate as a function of infantile handling and food deprivation level. Journal of Genetic Psychology, 1969, 115, 237-246.

Young, R. D. Drug administration to neonatal rats: Effects on later emotionality and learning. Science, 1964, 143, 1055-1057.

(R eceived for publication May 20, 1974.) 